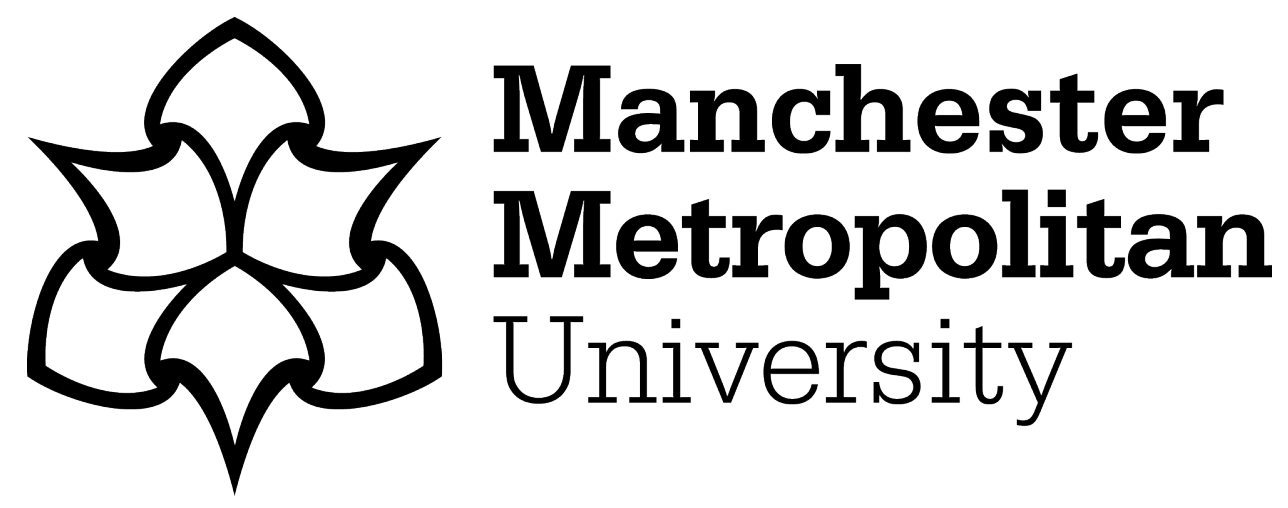

Skains, R Lyle (2020) Creative Writing Courses and the Pragmatics of Publishing. In: Contemporary Publishing and The Culture of Books. Routledge. ISBN 9780367443153

Downloaded from: https://e-space.mmu.ac.uk/625719/

Version: Accepted Version

Publisher: Routledge

Please cite the published version 


\title{
8
}

\section{Creative Writing Courses and the Pragmatics of Publishing}

\author{
R. Lyle Skains
}

\section{Introduction}

Writing for publishing is a specific topic that was rarely covered in my undergraduate and postgraduate programmes in creative writing, though the dominant assumption of the creative writing workshop is that the students' goals are always to become published authors. When it was covered, it was always in terms of the mechanics of submission: crafting the query letter, honing the first three chapters to perfectly hook the reader, and how to find agents and editors who might accept the work. When I began teaching aspects of writing for publishing as a postgraduate teaching assistant, though I had been published several times, I still had very little idea of how the publishing industry worked, much less its history or strategies. The workshop-dominant structure of my undergraduate and MFA in creative writing, like most, failed to prepare me thoroughly for publishing my own writing and for teaching other creative writers how to publish - particularly in today's volatile digital environment. Teaching creative writing has evolved beyond the workshop (for many reasons, including diversity and authority); to best serve our students, it calls for a multipronged, mixed-methods approach that prepares students not only in terms of critical thinking and craft, but also in terms of skills and vocation.

Creative writing in higher education is generally acknowledged to have begun in the Iowa Writers Workshop in the 1930s (Bishop, 1990; Fenza, 2000; Brayfield, 2009; Vanderslice, 2010; Bennett, 2014). Its creators, Norman Foerster followed by Paul Engle (Fenza, 2000), created it to provide a community for writers to hone their talent, not to teach writing; their philosophy was that writing could not be taught, merely nurtured (Bishop, 1990; Donnelly, 2010). Stephanie Vanderslice notes it was created for polished writers, to toughen them up for facing critics, and largely consisted of men attending university on the U.S. G.I. Bill (2010, pp. 30-32); its assumptions were that its students were homogenous in their culture, experience, commitment, and ability (Haake, 1994, p. 80). The workshop itself is highly restrictive: the number of students is limited, with 10 noted as an ideal; its focus is on writing, and rarely reading outside the workshop pieces; it institutes a "gag rule" silencing the author whose work is being discussed; it focuses on flaws in the work according to the group consensus rather than publishing or audience analysis; it focuses on the final product over the process of producing work; it is usually restricted to the "the three-headed Iowa canon" of minimalist realism, verbose realism, and magical realism (Bennett, 2014, p. n.p.), eschewing all other genres in its servitude to literature (Bizzaro, 2010, p. 38). Its model is one that persists despite changes in the student body, universities, and publishing industry, mostly because its instructors simply teach as they themselves were taught (Amato and Fleisher, 2001); for example, Gill James' presentation of her workshop model differs little from Paul Engle's early $20^{\text {th }}$ century construction (2009). 
Yet creative writing researchers and instructors have been urging their peers to update their teaching methods for decades. They have condemned the Iowa model as an invitation to "laziness, calcified thinking and emotional abuse" (Kennedy, 2012, p. 202), an oppressive space that perpetuates patriarchy and bourgeois economics (Koehler, 2015, p. 17) and silences many who may already feel alienated and disempowered (Kearns, 2009, p. 794) in a multicultural and multilingual community (Brayfield, 2009, p. 210). It places ultimate authority in the instructor, reifying a New Critical perspective that privileges "norms" of literature rather than encouraging writers to experiment (Bizzaro, 1994, p. 238), focusing on polishing writing and pushing it toward this "common, safe, and neutral ground" (Webb, 1990, p. 332) and actively suppressing minority voices and avant-garde expression (Amato and Fleisher, 2001). Wendy Bishop argues for a "transactional workshop" led by students and empowering the author's voice to direct their own feedback, situated in the context of their goals and practice (1990). Most creative writing pedagogical discourse echoes this notion and builds upon it, espousing student-led workshops (Bizzaro, 1994; Amato and Fleisher, 2001), encouraging integration of cultural discourse and theory (Garber and Ramjerdi, 1994; Ostrom, 1994; Donnelly, 2009; Haake, 2010; Vanderslice, 2010; Kostelnik, 2014), and development of critical thinking and transferable skills that are more applicable to the modern digital workforce (Cope and Kalantzis, 2009; Clark, 2010; Moxley, 2010; Brandt, 2015; Koehler, 2015).

If creative writing in higher education's goal is to produce published writers, then we must acknowledge the significant changes occurring in the publishing industry; it is no longer sufficient to teach the art of the query letter to $21^{\text {st }}$ century authors. While royalty publishing is certainly not obsolete, nonetheless publishing has become democratized: the digital age has produced a writingliterate culture (Brandt, 2015) that is already participating in mass authorship (Laquintano, 2016). Timothy Laquintano defines publishing both as a professional practice and as "a literacy practice that develops under conditions in which ordinary people have the ability to publish their writing using digital infrastructures" (ibid., 12), leading to mass authorship. Writers who intend to participate within these practices must be aware of the trends in the industry (which necessitates knowledge of its history and structures) and their options within and without it. Creative writing continues in the traditional form of the book distributed via royalty publishing; it is also erupting in indie publishing through ebooks and print-on-demand, fan fiction on sites like Wattpad and Archive of Our Own, and digital-born forms like Twine games and webcomics. Authors are utilizing alternative funding models, including crowdsourcing through Kickstarter and Unbound and patronage through Patreon, as well as mixed media forms, including interactive narratives, podcasts, and transmedia texts (Skains, 2019). Digital media make publication easy for creative writers; it also introduces new contexts, forms, and considerations such as how to find and grow audiences in such fragmented spaces of attention (Goldhaber, 1997; Bhaskar, 2013).

The result of these various shifts in creative writing and publishing contexts calls for not just updates to the pedagogical model of the Iowa workshop, but for broader inclusion of publishing and writing for publishing in creative writing programmes. The study of publishing in higher education is a much more recent trend than creative writing, emerging only in the 1970s (Geiser, 1997). Publishing as an academic subject has largely remained a distinct study from creative writing, focused primarily on the business aspects of what has often been called an "accidental" profession (Greco, 1990, p. 18) - despite the clear overlap of creative and business endeavours. Indeed, many students of creative writing enter the publishing industry as editors (Logan and Prichard, 2016; What can I do with a creative writing degree?, 2018). In order to best prepare our writing students 
for their careers - whether they be published authors, editors, or other vocations drawing on their multiliteracy skills - it is vital to expand their rudimentary understanding of professional writing and publishing, and to dissuade their Romantic notions of creative genius in favour of developing robust process and critical thinking skills.

Toward that end, this essay models two undergraduate modules I have developed combining creative writing and publishing: Professional Publishing and $21^{\text {st }}$ Century Writing \& Publishing. The following sections discuss the ways that digital technology and economic and administrative challenges have changed the creative writing student and classroom. This discussion is followed by descriptions of each module, and the pedagogical philosophies behind their structures. A discussion section ensues, parsing this approach with regard to meeting student, instructor, university, and even cultural goals for the creative writer.

\section{Creative Writing in Today's Higher Education Environment}

Digital technologies, like many technologies before, are changing what it means to write and publish. The Romantic notions of the writer as an isolated, creative genius and the publisher as an arbiter of taste and culture cannot hold up in today's environment of microblogging, indie publishing, fan fiction, and risk-averse publishing economies (if they were ever accurate at all). Contemporary publishing can mean posting on a blog, constructing a fictional Twitter persona, formatting an XML file for indie ebook distribution, crafting hypertexts and literary games, launching a Kickstarter campaign - or a combination of all of the above, and then some (Moxley, 2010; Laquintano, 2016; Skains, 2019). For creative writers to succeed in a context where "writing has widened beyond the page" (Koehler, 2015, p. 26), they must be literate in more than just the three-act structure. A multiliteracies approach (Cazden et al., 1996; Cope and Kalantzis, 2009) is called for, wherein students can gain practical experience, the ability to conceptualize their experiential knowledge and analyse their work and the work of others with regard to relationships of power, and the ability to apply all of this to work in the real world.

This same digital technology has also altered the audiences for creative writing. Despite pessimistic claims that the book is dead and literature along with it, audiences read more now than they ever have before-just in more media than the mere codex. Creative narratives occur in many spaces, including books, ebooks, blogs, fan fiction sites, social media, games (Ensslin, 2014), Reddit forums (Alexander, 2016), and even ecommerce reviews (Skains, 2018). The book-or rather, the narrative, as the materiality of the book dissolves in digital spheres -is enabled as a read-write medium (Lessig, 2008; Laquintano, 2016), wherein the boundary between readers and writers is permeable, texts are mutable, and even the most fringe genres can find a home and audience. This fracturing of the $20^{\text {th }}$ century communication hierarchy of author->fixed text->reader has fragmented audiences in a many-to-many democratization of media communication, thinning attention to any one form, genre, or author. Today's writers and publishers compete in an attention economy, as our ability to consume media has been far outpaced by our collective ability to create new texts (Goldhaber, 1997); everyone can create, thanks to digital media, but it's harder than ever to collect more than a modicum of the audience required to convert that attention capital into cultural or financial capital. 
In addition to the writing and publishing world they will encounter once they depart our hallowed university halls, the culture and economy within our institutions have changed significantly since the formation of creative writing programmes in higher education. Foerster and Engle's dedicated (and distinguishing) community of critique for writers with established talent has evolved into a cash cow market for universities (Hancock, 2008; Simon, 2015), particularly in an age of austerity. The drive to recruit more students paying higher fees, combined with government-driven efforts to widen participation in higher education (Leathwood and O'Connell, 2003) have resulted in creative writing programmes with a diverse set of students in terms of experience, culture, motivation, and career goals. The perception that a university education boosts career prospects and earningsaside from any loftier goals of creating better citizens-leads to pressure on universities for development of "transferable skills", i.e., vocational training applicable to the wide range of careers that students of English and creative writing matriculate into: design, media, arts, business, marketing, public relations, and sales (Logan and Prichard, 2016; What can I do with a creative writing degree?, 2018). The pressure is thus on creative writing instructors not only to hone the creative writing techniques of a non-homogenous, ever larger group of students, but also to "scaffold students' development of critical thinking, communication, collaboration, problem-solving, and metacognitive skills necessary to thrive in the complex and globalized society of the futureand today" (Howe and Van Wig, 2017, p. 139).

Likewise, this non-homogenous group of creative writing students has a non-homogenous set of goals. Katharine Haake notes that in the beginning, creative writing programmes were designed primarily to enable students to become published writers, and secondarily to become creative writing teachers (1994, p. 79). The students entering our programmes, however, have distinct and complex goals for themselves. Most are seeking assurance that they can write, overcoming the stilldominant Romantic myths about creative genius (Bishop, 1990, p. 2), not only to confirm their own capabilities but also to determine if creative writing is the best vocation for their abilities (Webb, 1990, p. 333). Bishop also notes that many enrol in writing programmes "for the structure and prompting and prodding, for the demands and deadlines and activities that will help them generate new work" (1990, p. 62). Many of my students enter their programme with the anticipated goal of becoming a "published author", generally defining this as the narrow notion of having a novel published by a royalty publisher. Most of them leave, however, with a much wider knowledge of the possibilities for writing careers, including web writing, indie publishing, media production, screenwriting, playwriting, writing for games, journalism, feature writing, travel writing, and much more. It is insufficient to simply play into their naïve expectations of writerly ideals; as $21^{\text {st }}$ century creative writing instructors, we have an obligation to expose them to as many possibilities for their success as possible.

This can be a daunting task for creative writing instructors, particularly as the Iowa model rarely leaves room for training them as teachers, leading them to simply mimic the way they were taught (Amato and Fleisher, 2001). We have largely been indoctrinated to the strictures of the creative writing workshop—-the "gag rule", focus on flaws, and realism genres — which perpetuate "patriarchal forces and bourgeois economics that, ultimately, turn the fiction workshop into a politically and culturally oppressive space" (Koehler, 2015, p. 18). To better serve our students and their potential for significant contribution to culture, we as creative writing instructors need to abandon this constrictive model that assumes a certain type of student and privileges a particular approach to literature; in fact, we need to break free from the notion that as creative writing instructors and students that we are in service to literature. My goal as an instructor is to arm my 
students with creative writing skills, yes, but also to instil multiliteracies: to develop their critical thinking skills, to empower them to break free of canonical expectations and socio-cultural power structures, to take the processes and practices they learn on their modules and be able to apply them to their life and career post-university.

The challenge for instructors is to create a classroom/programme environment that permits pursuit of the goals of all parties involved: students, instructors, and universities. Students want to be "good writers"; because of the dominant cultural and educational models, they expect to become good writers by sitting in workshop circles, ideally with prominent writers telling them how to do it "correctly". As instructors, we know that excellent writers are not necessarily excellent teachers, and vice versa; we are beginning to understand that the workshop model has fundamental flaws. So as we try to introduce alternative methods, we face resistance from students, as we are not meeting their inexperienced expectations. The pressures of measures such as the UK's National Student Survey, RateMyProfessor.com, and universities' financial need to please students as customers further complicate the maze of expectations instructors must negotiate. Universities want us to match marketing campaigns and do whatever will make our students/customers give us excellent scores on the litany of surveys and evaluations that pretend to measure teaching quality; it is difficult to push back on both these fronts to meet our own goals of empowering creative writers as purveyors of culture and as citizens of the modern world.

Nonetheless, that is what I have sought to do in developing the various modules I teach, and in particular the writing and publishing modules profiled in this chapter. Publishing is not often taught in parallel with creative writing in the workshop model-when it is, it rarely pushes the creative writer into the digital age, exposing them to the multitude of publishing, distribution, and monetization platforms that are enabling writers to reach their audiences and make a living. I attempt to fill that gap with the modules I offer, not only building my students' creative and vocational skillsets, but also incorporating pedagogical techniques that improve their multiliteracy skills, better preparing them for the changing demands of the current workforce, for the power imbalances in their social structures, and for navigating issues of self and culture in digital environments.

\section{Teaching Writing for Publishing: Model Modules}

I have taught various "writing for publishing" modules over the last decade or so, and my methods have evolved significantly. Early on, I focused on what I myself had been taught: how to write for a market (commercial rather than literary; as a speculative fiction enthusiast, I greatly resented being forced to write literary fiction as a creative writing student), and how to get agents and editors on board with a particular novel project. I had little awareness of the history of publishing, the work of editors, the trends in the current industry, and what developments were on the horizon. My research interest in digital media and its effects on creative writing, however, led me to widen my focus to include its effects on publishing creative writing, and my growing awareness that the publishing industry is in the midst of a paradigm shift of Gutenberg proportions. Thus I continually push my modules to include discussion and evaluation of this shift, to better prepare my students for the writing and publishing atmosphere they will launch themselves into. The two modules profiled here, Professional Publishing and $21^{\text {st }}$ Century Writing \& Publishing, immerse students in 
current publishing trends, arming them with creative and analytical skills to traverse this everevolving landscape.

\section{Professional Publishing}

I created "Professional Publishing" to meet the needs of a select few third year students in our creative writing programme, thus it was a small module of four. The module's aims for the students were simple: to gain professional skills in writing, editing, and publishing creative writing in the current marketplace; to gain experience working in professional groups; and to gain awareness of publishing industry trends. All students on the module were members of the "Editorial Board"; the instructors (my colleague Eben Muse and I) were the "Editors-in-Chief". The Editorial Board was tasked with writing, commissioning, editing, designing, and publishing a collected volume of creative writing by the end of the semester. The requirements for this volume were: 1) it must be published as both a print-on-demand and reflowable ebook with the major online booksellers; and 2 ) it must reflect positively on the publishing body (the university).

The assessments were designed in approximation of Linda B. Nilson's "specifications grading" (2014), in which the module incorporates multiple pass/fail assessments-the more passing marks, the higher the overall module mark ${ }^{1}$. The assessments were part of the editorial and publishing process: 1 ) a 3000 -word creative piece for the collection; 2) a commissioned short story for the collection; 3) two developmental editorial reviews of submitted stories; 4) two copyedits of submitted stories; 5) layout/design of two of the stories; and 6) peer reviews for each of the weekly editorial board meetings. All assessments, however, were not mandatory; in order to achieve a passing mark (D in our university's A-F scheme), students only had to perform satisfactorily in assessments 1 (creative work), 3 (editorial reviews), and 6 (peer reviews); the more satisfactory assessments a student completed, the higher their overall mark (see Table 1). Assessments 4-6 were marked pass/fail; assessments 1-3 were marked according to the decisions of the Editors-inChief as to acceptance of each piece for publication: "Publish as-is" (an A mark); "Publish, minor editing" (B); "Reject; editing required" (C); "Reject; significant editing required" (D); and "Reject" (F). A token system, with three initial tokens per student, allowed students to trade a token to revise and resubmit a piece for a better decision; students could also trade tokens amongst one another in return for favours, such as help editing with a difficult piece, or copyediting if that was not a particular student's strength.

<COMP: Place Table 8.1 Here>

Only half the module topics are planned in advance: coverage of practicalities such as promoting a call for works, conducting various levels of edit, marketing strategies, publishing options, technical lessons on design and layout, and copyright issues. The students, based on their self-identified needs, can request remaining scheduled lecture sessions. These included author contracts, budgeting, working in groups, and organising a book launch. The Editorial Board sets their own schedule and deadlines for each assessment based on the final deadline for publishing the collection, and each student performs various group roles in their weekly meetings and throughout the semester: chair, secretary, treasurer, marketing officer, etc. By midway through the semester, the Editors-in-Chief very much served an advisory role, aiding with group conflicts as we would in any workplace, reviewing the submitted work as scheduled, and identifying resources as necessary. 


\section{$21^{\text {st }}$ Century Writing \& Publishing}

$21^{\text {st }}$ Century Writing \& Publishing is an on-going module that I have taught, progressing through various iterations, for around eight years. In its current iteration, it is a joint module for secondand third-year undergraduates, taught every other year. Its aims are focused on developing understanding of digital publishing and epublishing; developing proficiency in designing narratives for publication; and understanding the effects of digital media on publishing, writing, and reading narrative in current environments, including relevant critical theory. Students on this module write a piece of original fiction in a chosen medium (prose or digital fiction) and submit it for publication or self-publish the work. The module often involves advanced hypermedia techniques, writing in multiple modes of communication, and questions about the economic possibilities for writers in the digital age.

This module, too, incorporates a specifications grading model, in a three-pronged approach. Students complete weekly tasks developing two individual assessments: the creative work for publication, and an argumentative essay based in the practice of writing and publishing their creative work. The third assessment incorporates on-going discourse to the module; its form has changed over the years, from participating in weekly blogs or discussion forums on module topics to, currently, group student-led seminars. The student groups are each assigned a week to lead seminar discussions and exercises based on the relevant critical and creative readings assigned that week. These sessions are peer-reviewed; the mark on this assessment incorporates both performance in leading the seminar discussion for the group, and submitting individual peer reviews for all the other groups. All tasks assigned for this module are marked on a modified pass/fail system: 0 denotes a task that was not submitted; 1 denotes a submitted but failing task; 2 denotes a pass; and 3 denotes an exceptional task, one that surpasses expectations in terms of critical thinking or incorporation of readings. Final marks for each of the three assessments are based on the number of satisfactory marks they receive for tasks related to the assessment: submitting and receiving mostly satisfactory "2" marks falls in the B-range, whereas mostly " 3 "s falls in the A-range. The minimum requirements for each assessment are the final deliverables: the published creative piece, the essay, and participation in leading a seminar. Because of the system, however, a student who only delivers the final product can earn a maximum mark in the D-range, regardless of the quality of that product (see sample marking rubric in Tables 2 and 3). As with Professional Publishing, each student is awarded tokens they can trade for resubmission of a "1" task or submission of a late task.

<COMP: Place Table 8.2 Here>

<COMP: Place Table 8.3 Here>

The topics covered on the module progress from a look at the history of royalty publishing and the establishment of copyright law, through digital book publishing to the current variety of genres and methods of publishing. These latter comprise the bulk of the semester: alternative funding methods such as crowdsourcing and patronage; interactive media and literary games; collaborative storytelling through social media and/or webcomics; serial publishing, blogging, and/or podcasting. For each method we examine successful case studies for creative readings. For critical theory readings, the reading list includes publishing history and trends, the effects of disruptive technologies, copyright history and trends, and digital and Internet culture. Some readings are of a more practical nature, such as how to format XML files or record and publish a podcast, and serve 
as resources for current and future projects. It is a very wide-ranging module, but the effect is that students get a good survey of the digital publishing landscape, and awareness that there is more to writing and publishing than the royalty model.

\section{Pedagogical Approaches}

My philosophy on teaching is shaped in large part on what I value as a writer, researcher, and teacher: I think writers should be well rounded in terms of knowledge, critical thinkers, and capable of working independently. The creative writing workshop at best helps them develop criticality; at worst it helps them develop biased criticality based on not much more than subjective and emotional opinions. Thus I have largely eschewed the workshop model in my classroom as I have progressed as an instructor (not to mention as enrolment numbers have soared beyond what is feasible for workshops), in favour of what Haake terms a "hybrid classroom", in which "the class is more or less evenly split between its reading and its writing expectations, ... the reading all proceeds from a writerly perspective and that the 'critical' work we do is always 'creative'" (2010, p. 187). The assessments are split between creative and critical; the weekly readings include both creative texts and critical cultural, literary, and publishing theory; and module discourse centres on the interchange between cultural and critical awareness and the writerly goals of contributing thoughtfully and critically to the art and culture of society.

As Kate Kostelnik notes, students are often resistant to this hybridity (2014, p. 439), desiring the much easier path to write, workshop, be told what to fix, and resubmit. Often, this resistance is reflected in these students' module evaluations, particularly for low-attending and/or -participating students; these students in particular generally fail to grasp how this combination of theory and practice aids them in their pursuit to be "good writers". Nonetheless, it is my duty as the instructor, as one who "knows better" and is supported by research (Bizzaro, 1994; Camoin, 1994; Haake, 1994; Ostrom, 1994; Kostelnik, 2014), to persuade them this hybridity benefits them, and to push back against university administrators who would urge me to alter my methods to make the students happy ${ }^{2}$, to the detriment of the creative writer who seeks to engage in matters of consequence through their published writing (Goodfellow, 2011, p. 138).

In order to meet both my pedagogical goals and those of my students-who wish not only to write, but to publish-I focus my modules on process rather than product. To be successful in reaching their goals as published writers, and to meet my goal of creating independently, they must be able to continue their creative work once they have graduated, and no longer have the luxury of a room full of peers and an instructor to provide structure, deadlines, and feedback. For one, the creative writing classroom is often a biased one, led by instructors with subjective preferences and filled with students who have internalized the Iowa model's notions of talent and privileging of literary fiction (Bishop, 1990). The creative writing classroom as an audience is not reflective of all audiences; it is more beneficial to the creative writing student to develop the ability to analyse their audience, their genre, their publishing culture, and adapt their writing to fit-and vice versa, to be able to analyse their own work and place it within the appropriate publishing and readerly contexts. By assigning marks according to the process of creating their final assessments, my own bias as an instructor-bias about what genres I like, which students I like, what type of writing or media I like-is mitigated. Likewise, by asking students to publish their work in an appropriate 
publishing pathway and analyse those choices, they develop a practice of critical thinking that can be used in their future contexts of writing and publishing.

In addition to developing these independent skills, this model empowers them in their writing process, boosting their confidence as writers, thinkers, and workers in general. Bishop advocates for a "transactional workshop", in which peer-to-peer interaction is preferred over the hierarchy of teacher/expert-led instruction (1990); in the transactional workshop, the writer leads the discussion of their work, rather than passively taking the "beating" inherent in the workshop model. The transactional workshop is much preferred particularly for writing and publishing modules, as it leaves room for the students to have authority over the knowledge of their genre, medium, and audience; it is impossible for the creative writing instructor to be "expert" across the wide range of niche audiences and quickly emerging publishing platforms (each year I have to delete the defunct and add the new) available to today's digital author. Re-distributing this authority from the instructor to the student empowers the student to pursue their particular goals, and the class as a whole to expose one another to the astonishingly wide array of publishing possibilities. It also "de-apprentices" the creative writing classroom, wherein the hierarchy of instructor-as-expert drives the students to appropriate the instructor's way of working, style of writing, and pathway to publication (Bizzaro, 1994, p. 242), leaving the student freer to establish independence and ostensibly greater originality in their writing endeavours.

From my perspective, Professional Publishing and 21 st Century Writing \& Publishing have been highly successful modules. While the former was a one-off module for only four students, the work they produced was of professional quality; two of the students have gone on to form their own imprint and continue to commission and publish short fiction anthologies. The latter has resulted in an impressive array of published works, including podcasts, Twine games, interactive blogs, Kickstarter novels, indie published ebooks, webcomics, and even a few traditionally submitted query letters. Students have used an incredible array of publishing platforms: Amazon Kindle Direct Publishing, social media, Patreon, Wattpad, Kickstarter, podcasting, and Storify. Most of these are genres and platforms in which I have very little practical experience, which indicates the teaching model I have incorporated is "de-apprenticing" my students from my own practice, and empowering them within their own practice to analyse and pursue pathways that best suit their writing.

\section{Discussion \& Conclusions}

The approach I've taken with my writing and publishing modules is an attempt to meet the varied goals of all parties involved: student, instructor, and university. Students who want to write creatively in any way as part of their careers benefit from experiential knowledge, linking learning, thinking, and doing (Rhodes and Roessner, 2009, p. 305). The publishing industry expects more and more out of its writers, whether they opt for royalty or indie publishing. Thanks to fracturing audiences amongst media and publishers, royalty publishers are cutting costs in any way they can, which includes favouring "celebrity" authors who already have significant attention capital, and reducing the number of unknown properties (or even mid-list authors) they take on. It also includes reducing services to the authors they do publish, "placing increased obligations on authors to become involved in the management and dissemination of work" (Baverstock and Steinitz, 2013, p. 211), and focusing marketing efforts on niche audiences while spreading content across diverse 
media channels (Thompson, 2012, p. 247). Writers no longer have the luxury, even when working with royalty publishers, of turning in a manuscript and simply allowing the wheels of the industry to churn their work out for them (if they ever really did).

Alternatively, writers now have a multitude of options open to them for publishing their own work-often in combination with royalty publishing. The stigma of self-publishing is fading away in light of the indie published successes of Hugh Howey, Marco Koska (Flood, 2018), and even E.L. James. By exposing students to the variety of options and asking them to evaluate and choose those that best suit their writing and practice, students gain valuable insights into the industry in which they want to work, and experiential knowledge that gives them confidence in their future writing and publishing endeavours (Baverstock and Steinitz, 2013, p. 221). This confidence grows as well from the greater authority they are given in the classroom, as the instructor facilitates knowledge and advises students rather than dictates choices (Rhodes and Roessner, 2009), developing not only their writing and publishing skills but also group coordination, presentation, research, analysis, and problem-solving abilities. This multiliteracies approach is designed to arm them with critical transferable skills that will serve them well regardless of their eventual career outcomes.

Integrating theory and practice in their multiliteracy practices also has significant personal and socio-cultural effects for creative writing students. The history of English literature is strongly embedded in socio-cultural discourse, as Terry Eagleton describes its rise as a binding agent, as it were, for Anglo-American culture in the wake of religious fragmentation, cultural revolutions, and rising literacy (2008). Yet the Iowa workshop model is criticized for its homogeneity, its silencing of disparate voices, and its perpetuation of narrowly defined and increasingly out-dated literary "norms"; creative writers must be exposed to a wide variety of discourse and voices, both within their own culture and without, in order to contribute in a meaningful way to culture. They must be aware of the conversations they are entering, of the power structures they are participating in as writers, as publishers, and as readers, not only to navigate them for their own sake, but to effect change in their role as cultural reflectors and prognosticators. As Mary Ryan notes:

\section{The arts are powerful spaces to interrogate how our own personal understandings are mediated by contexts of schooling, curriculum and sometimes by hegemonic views of the world - important considerations in becoming literate in a rapidly changing, globalised world (2014, p. 5).}

Students cannot gain this literacy without reading and synthesizing both theory and creative texts from diverse voices on diverse topics.

Gaining a more nuanced cultural perspective, as well as exposure to the wealth of publishing options, also serves both student and instructor goals: it often leads to innovations in their writing. I find my students are often very concerned with the notion of originality, enough to keep many from progressing in their work. It is difficult to write "the new" if you are unaware of what has come before, or what options are available for your work. Digital media have opened up a wide array of writerly options: indie publishing, blogging, social media, podcasting, serials, digital fiction, games, collaborative writing, interactive storytelling, multimedia storytelling, transmedia storytelling, and much more. It has expanded the form and structure of narrative, opening new pathways not only for publishing, but for creative story construction. For students who worry that nothing they do is unique, simply trying something new can lead to astonishing creativity, which 
writers crave; it is no coincidence that the ebook "revolution" was driven not by business writers, as expected, but by fiction writers (Thompson, 2012, p. 322).

This is not all to say that I have perfected the module models I have presented here. I plan a number of future interventions in these modules to further address balance of authority, multiliteracies, and writer ownership of their texts. Bishop advocates against a lecture-based teaching model, which reinforces student passivity (1990), a significant issue in British-educated students whose secondary school structures indoctrinate them in passivity, hierarchy of authority, and rote memorization. It is also an issue given the push by British universities to recruit more and more students - not all of them are equally enthusiastic about their studies, an imbalance that many creative writing instructors note leads to rushed or incomplete work and failure to read assigned texts (Donnelly, 2010, pp. 12-13). When teaching writing and publishing theory and history, however, I find it quite easy to fall back into the lecture structure, particularly as I rarely have to prepare anything from scratch anymore. A simple solution I have used in the past is to assign the readings with key discussion questions, and then give the students time at the beginning of a "lecture" session to discuss these in groups, perhaps even filling in a worksheet with their responses (which keeps them on task). Ideally, I will also assign students a weekly exercise task regarding these readings, so they will have engaged on several levels with the material before turning to me for interpretation and explanation. Once their group discussion winds down, I ask them to share their observations and questions with the entire class for a larger discussion. I always tell the students that if these discussions take the entire "lecture" session, and I never get to my lecture notes, then great! They've read and synthesized the material via these activities far more than they would by falling asleep to the sound of my voice. It also puts more authority in their hands, as they are responsible for preparing for class ahead of time with the exercises and discussion questions, and for contributing to the discussion.

I am also planning to revise my critical essay assessments. While these are standard academic learning tools, and arguably an effective method for teaching and evaluating key multiliteracies skills such as research, written communication, and critical thinking, they are a very specific task for a very specific career: academia. Students and universities are both placing more vocational expectations on their studies, and only a small percentage of these students will go on to postgraduate work-even smaller to careers in academia. Knoeller argues for "imaginative response", offering students a wide array of discourse-based options, both creative and critical, for responding to the readings and topics covered on a module (2003). I have often given exercises of this sort, for example, responding to a short story with a creative work of Bakhtinian discourse. Opening their argumentative essays into alternate forms such as feature articles, proposals, fictocriticism, wikis, and other creative responses gives them a more personally meaningful mechanism through which to synthesize and display what they've learned on the module. It also develops relevant multiliteracies for creative writers who do not plan to enter academia, but may eventually write nonfiction work for other purposes, such as websites, business, law, and others.

The goal of creative writing programmes since their inception has been to produce published authors; the goal of students on these programmes has been to hone their skills to that professional level. It is startling, then, that creative writing and publishing have not been integrated more as complementary studies in higher education. Particularly in the current era, when digital media is so vastly transfiguring the landscape of both, it is vital that creative writing students gain understanding of and experience with publishing practices and power structures. Embracing a 
multiliteracies pedagogy, emphasizing student-led activities, integrating theory and practice from diverse voices, and focusing on process rather than product enables a classroom in which creative writers can develop their voice, find their audience, and innovate through new forms and publishing pathways. The skills they gain not only enhance their abilities as creative writers seeking to become published authors, but also as workers entering a diverse and globalised economy. By demolishing the creaking century-old structure of the Iowa workshop, we as creative writing instructors can scaffold our students with innovative, flexible, and insightful practices that will benefit our classrooms, their careers, and our culture as a whole.

Table 8.1 Final Marking Table

\begin{tabular}{|c|c|c|c|c|c|}
\hline \multirow[t]{2}{*}{ Satisfactory Assessment } & \multicolumn{5}{|c|}{ Marking Ranges } \\
\hline & A & B & C & D & $\mathrm{E}$ \\
\hline 1. Creative Work & $\bullet$ & - & • & - & • \\
\hline 2. Commissioned Work & $\bullet$ & $\bullet$ & & & \\
\hline 3. Editorial Reviews (2) & $\bullet$ & $\bullet$ & • & $\bullet$ & \\
\hline 4. Copyedits (2) & $\bullet$ & $\bullet$ & $\bullet$ & & \\
\hline 5. Layout Design/Edits (2) & $\bullet$ & $\bullet$ & & & \\
\hline 6. Peer Reviews & $\bullet$ & $\bullet$ & $\bullet$ & $\bullet$ & $\bullet$ \\
\hline $\begin{array}{l}\text { Average "excellent" peer } \\
\text { review of performance }\end{array}$ & - & & & & \\
\hline $\begin{array}{l}\text { "Publish as-is" decisions on at } \\
\text { least two of: } \\
\text { - } \quad \text { Student's own work } \\
\text { - } \quad \text { Edited works }\end{array}$ & • & & & & \\
\hline
\end{tabular}

Table 8.2 Task breakdown for creative assessment

MINIMUM REQUIREMENT to PASS

\section{Creative Portfolio}

2000-word work of creative writing, created and published (or submitted for publication) during the semester.

OPTIONAL TASKS for HIGHER MARKS

\section{Creative Exploration Task}

Submit 3 creative exercises in different media, with a 200-word discussion on how they influenced the creative choices for your portfolio.

\section{Pitch Peer Assessment Task}

Submit 3 Peer Assessment reviews of fellow students' creative pitches. 


\section{Peer Workshop/Beta-Test Task}

Complete and submit feedback for at least 3 peers on their creative portfolio.

\section{Revision Task}

Describe how you used the workshop feedback you received on your creative work to revise the work. Max 200 words.

Table 8.3 Creative assessment marking criteria

\begin{tabular}{|c|c|}
\hline Mark & Criteria \\
\hline $\mathrm{A}$ & $\begin{array}{l}\text { Meets all of the D-level standards, plus all } 5 \text { elements received } 3 \\
\text { marks. } \\
\text { A+ Work exceeds professional standards in terms of innovative } \\
\text { approaches to creativity and/or publication. } \\
\text { A Work achieves basic professional standards. } \\
\text { A- Work needs some revision in order to achieve professional } \\
\text { standards/recognition. }\end{array}$ \\
\hline B & $\begin{array}{l}\text { Meets all of the D-level standards, plus: } \\
\text { B+ Four tasks submitted, and at least three of five elements } \\
\text { received } 3 \text { marks } \\
\text { B Four tasks submitted at } 2 \text { level } \\
\text { B- Three tasks submitted at } 2 \text { level }\end{array}$ \\
\hline $\mathrm{C}$ & $\begin{array}{l}\text { Meets all of the D-level standards, plus: } \\
\text { C+ Two tasks submitted, and at least two of three elements } \\
\text { received } 3 \text { marks } \\
\text { C Two tasks submitted at } 2 \text { level } \\
\text { C- One task submitted at } 2 \text { level }\end{array}$ \\
\hline
\end{tabular}




\begin{tabular}{|c|c|}
\hline $\mathrm{D}$ & $\begin{array}{l}\text { Creative work sufficiently demonstrates the achievement of Learning } \\
\text { Outcomes (LOs). } \\
\text { D+ Work exceeds minimum standards } \\
\text { D Work is sufficient to meet minimum standards } \\
\text { D- Work is insufficient in some aspects of creative and/or } \\
\text { publication execution }\end{array}$ \\
\hline$E$ & $\begin{array}{l}\text { Portfolio insufficient to demonstrate achievement of LOs. } \\
\text { E+ Work approaches achievement of LOs, but has poor clarity of } \\
\text { expression or significant deficiencies in its structures } \\
\text { E Work is insufficient in } 1 \text { LO } \\
\text { E- Work is insufficient in } 2 \text { LOs }\end{array}$ \\
\hline $\mathrm{F}$ & $\begin{array}{l}\text { Portfolio insufficient to demonstrate achievement of LOs. } \\
\text { FI Work was not submitted for publication } \\
\text { F2 Work is insufficient in all } 3 \text { Los } \\
\text { F3 Work is incomplete } \\
\text { F4 Work not submitted }\end{array}$ \\
\hline
\end{tabular}

\section{References}

Alexander, L. (2016) '_9MOTHER9HORSE9EYES9: the mysterious tale terrifying Reddit', The Guardian, 5 May. Available at:

https://www.theguardian.com/technology/2016/may/05/9mother9horse9eyes9-themysterious-tale-terrifying-reddit (Accessed: 17 June 2016).

Amato, J. and Fleisher, H. K. (2001) 'Reforming Creative Writing Pedagogy: History as Knowledge, Knowledge as Activism', Electronic Book Review, 12. Available at: http://www.altx.com/ebr/riposte/rip2/rip2ped/amato.htm (Accessed: 4 October 2018). 
Baverstock, A. and Steinitz, J. (2013) 'Who are the self-publishers?', Learned Publishing, 26(3), pp. 211-223. doi: 10.1087/20130310.

Bennett, E. (2014) 'How Iowa Flattened Literature', The Chronicle of Higher Education, 10 February. Available at: https://www.chronicle.com/article/How-Iowa-Flattened-Literature/144531 (Accessed: 4 October 2018).

Bhaskar, M. (2013) The Content Machine: Towards a Theory of Publishing from the Printing Press to the Digital Network. London: Anthem Press.

Bishop, W. (1990) Released into language: options for teaching creative writing. Urbana, Ill: National Council of Teachers of English.

Bizzaro, P. (1994) 'Reading the Creative Writing Course: The Teacher's Many Selves', in Bishop, W. and Ostrom, H. A. (eds) Colors of a Different Horse: Rethinking Creative Writing Theory and Pedagogy. Urbana, IL: National Council of Teachers of English, pp. 234-247.

Bizzaro, P. (2010) 'Workshop: An Ontological Study', in Donnelly, D. (ed.) Does the Writing Workshop Still Work? Multilingual Matters, pp. 36-51.

Brandt, D. (2015) The Rise of Writing: Redefining Mass Literacy. Cambridge: Cambridge University Press.

Brayfield, C. (2009) 'Babelfish Babylon: Teaching Creative Writing in a Multi-Literate Community', New Writing, 6(3), pp. 201-214. doi: 10.1080/14790720903556189.

Camoin, F. (1994) 'The Workshop and Its Discontents', in Bishop, W. and Ostrom, H. A. (eds) Colors of a Different Horse: Rethinking Creative Writing Theory and Pedagogy. Urbana, IL: National Council of Teachers of English, pp. 3-7.

Cazden, C. et al. (1996) 'A pedagogy of multiliteracies: Designing social futures', Harvard Educational Review; Cambridge, 66(1), p. 60.

Clark, J. E. (2010) 'The Digital Imperative: Making the Case for a 21st-Century Pedagogy', Computers and Composition, pp. 27-35.

Cope, B. and Kalantzis, M. (2009) “'Multiliteracies”: New Literacies, New Learning', Pedagogies: An International Journal, 4(3), pp. 164-195. doi: 10.1080/15544800903076044.

Donnelly, D. (2010) Does the Writing Workshop Still Work? Multilingual Matters. 
Donnelly, D. J. (2009) Establishing Creative Writing Studies as an Academic Discipline. PhD. University of South Florida.

Eagleton, T. (2008) Literary Theory: An Introduction. Anniversar. Minneapolis, MN: University of Minnesota Press.

Ensslin, A. (2014) Literary Gaming. Cambridge, MA: MIT Press.

Fenza, D. W. (2000) 'Creative Writing \& Its Discontents', AWP: The Writer's News, 1 March. Available at:

https://www.awpwriter.org/magazine_media/writers_news_view/2871/creative_writing_its_di scontents (Accessed: 4 October 2018).

Flood, A. (2018) 'French bookshops revolt after prize selects novel self-published on Amazon', The Guardian, 15 September. Available at: https://www.theguardian.com/books/2018/sep/15/french-bookshops-revolt-after-prizeselects-novel-self-published-on-amazon (Accessed: 16 October 2018).

Garber, E. and Ramjerdi, J. (1994) 'Reflections on the Teaching of Creative Writing: A Correspondence', in Bishop, W. and Ostrom, H. A. (eds) Colors of a Different Horse: Rethinking Creative Writing Theory and Pedagogy. Urbana, IL: National Council of Teachers of English, pp. 826.

Geiser, E. A. (1997) ‘Publishing education', Publishing Research Quarterly, 13(3), pp. 110-117. doi: $10.1007 / \mathrm{s} 12109-997-0003-2$.

Goldhaber, M. H. (1997) 'The Attention Economy and the Net', First Monday, 2(4-7), p. n.p. Available at: http://firstmonday.org/article/view/519/440 (Accessed: 29 December 2017).

Goodfellow, R. (2011) 'Literacy, literacies and the digital in higher education', Teaching in Higher Education, 16(1), pp. 131-144. doi: 10.1080/13562517.2011.544125.

Greco, A. N. (1990) 'Teaching publishing in the United States', Book Research Quarterly, 6(1), pp. 1219. doi: 10.1007/BF02683729.

Haake, K. (1994) 'Teaching Creative Writing if the Shoe Fits', in Bishop, W. and Ostrom, H. A. (eds) Colors of a Different Horse: Rethinking Creative Writing Theory and Pedagogy. Urbana, IL: National Council of Teachers of English, pp. 77-99. 
Haake, K. (2010) 'Re-envisioning the Workshop: Hybrid Classrooms, Hybrid Texts', in Donnelly, D. (ed.) Does the Writing Workshop Still Work? Multilingual Matters, pp. 182-193.

Hancock, P. (2008) 'Novel thinking', Times Higher Education (THE), 10 July. Available at: https://www.timeshighereducation.com/features/novel-thinking/402673.article (Accessed: 15 October 2018).

Howe, L. and Van Wig, A. (2017) 'Metacognition via creative writing: dynamic theories of learning support habits of the mind in 21st century classrooms', Journal of Poetry Therapy, 30(3), pp. 139-152. doi: 10.1080/08893675.2017.1328830.

James, G. (2009) 'The Undergraduate Creative Writing Workshop', Creative Writing: Teaching Theory \& Practice, 1(1), pp. 48-62.

Kearns, R. M. (2009) 'Voice of Authority: Theorizing Creative Writing Pedagogy', College Composition and Communication, 60(4), pp. 790-807.

Kennedy, A. L. (2012) 'Does that make sense? Approaches to the creative writing workshop', in Morley, D. and Neilsen, P. (eds) The Cambridge Companion to Creative Writing. Cambridge: Cambridge University Press, pp. 201-214.

Knoeller, C. (2003) 'Imaginative Response: Teaching Literature through Creative Writing', The English Journal, 92(5), pp. 42-48. doi: 10.2307/3650423.

Koehler, A. (2015) 'Screening subjects: Workshop pedagogy, media ecologies, and (new) student subjectivities', in Clark, M. D., Hergenrader, T., and Rein, J. (eds) Creative Writing in the Digital Age: Theory, Practice, and Pedagogy. London: Bloomsbury, pp. 17-28.

Kostelnik, K. (2014) 'Innovative Frameworks and Tested Lore for Teaching Creative Writing to Undergraduates in the Twenty-First Century', Pedagogy, 14(3), pp. 435-454.

Laquintano, T. (2016) Mass Authorship and the Rise of Self-Publishing. Iowa City: University of Iowa Press.

Leathwood, C. and O'Connell, P. (2003) “It's a struggle": the construction of the "new student" in higher education', Journal of Education Policy, 18(6), pp. 597-615. doi:

$10.1080 / 0268093032000145863$.

Lessig, L. (2008) Remix: Making art and Commerce Thrive in the Hybrid Economy. New York: The Penguin Press. 
Logan, E. and Prichard, E. (2016) What Do Graduates Do? HEFCU: Graduate Prospects Ltd. Available at: https://www.hecsu.ac.uk/assets/assets/documents/What_do_graduates_do_2016.pdf.

Moxley, J. (2010) 'Afterword: Disciplinarity and the Future of Creative Writing Studies', in Donnelly, D. (ed.) Does the Writing Workshop Still Work? Multilingual Matters, pp. 230-238.

Nilson, L. B. (2014) Specifications Grading: Restoring Rigor, Motivating Students, and Saving Faculty Time. Reprint edition. Sterling, Virginia: Stylus Publishing.

Ostrom, H. A. (1994) 'Introduction: Of Radishes and Shadows, Theory and Pedagogy', in Bishop, W. and Ostrom, H. A. (eds) Colors of a Different Horse: Rethinking Creative Writing Theory and Pedagogy. Urbana, IL: National Council of Teachers of English, pp. xi-xxiii.

Rhodes, L. and Roessner, A. (2009) 'Teaching Magazine Publishing through Experiential Learning', Journalism \& Mass Communication Educator, 63(4), pp. 303-316. doi: $10.1177 / 107769580806300403$.

Ryan, M. (2014) 'Reflexivity and aesthetic inquiry: Building dialogues between the arts and literacy', English Teaching, 13(2), pp. 5-18.

Simon, C. C. (2015) 'Why Writers Love to Hate the M.F.A.', The New York Times, 9 April. Available at: https://www.nytimes.com/2015/04/12/education/edlife/12edl-12mfa.html (Accessed: 15 October 2018).

Skains, R. L. (2018) ‘Dissonant Fabulation: Subverting Online Genres to Effect Socio-Cognitive Dissonance', Textus, (2), pp. 41-57.

Skains, R. L. (2019) The Digital Author: Publishing in an Attention Economy. Cambridge: Cambridge University Press.

Thompson, J. B. (2012) Merchants of Culture: The Publishing Business in the Twenty-First Century. 2nd edn. Cambridge: Polity Press.

Vanderslice, S. (2010) 'Once More to the Workshop: A Myth Caught in Time', in Donnelly, D. (ed.) Does the Writing Workshop Still Work? Multilingual Matters, pp. 30-35.

Webb, C. H. (1990) 'Teaching Creative Writing', Mississippi Review, 19(1/2), pp. 331-333. 
What can I do with a creative writing degree? (2018) Prospects.ac.uk. Available at:

https://www.prospects.ac.uk/careers-advice/what-can-i-do-with-my-degree/creative-writing

(Accessed: 23 September 2018).

1 I maintain a full breakdown of my specifications grading module model, including links to sample module documents, here: http://lyleskains.blogspot.com/2018/09/my-take-on-specifications-grading-or.html. Note that the Professional Publishing module was the first in which I had incorporated this model, and thus its structure has been modified since.

${ }^{2}$ It is important to acknowledge that I have a permanent position in a high-performing department, and therefore have a level of job security that is not afforded to many creative writers on zero-hour and other precarious contracts. In these cases, it is vital that instructors have the support of key faculty such as line managers and/or Directors of Teaching \& Learning. 